Research Paper

\title{
Conjugative transfer of resistance determinants among human and bovine Streptococcus agalactiae
}

\author{
Tatiana Castro Abreu Pinto, Natália Silva Costa, Ana Beatriz de Almeida Corrêa, \\ Ivi Cristina Menezes de Oliveira, Marcos Correa de Mattos, Alexandre Soares Rosado, \\ Leslie Claude Benchetrit \\ Instituto de Microbiologia Paulo de Góes, Universidade Federal do Rio de Janeiro, \\ Rio de Janeiro, RJ, Brazil.
}

Submitted: January 15, 201; Approved: March 14, 2014.

\begin{abstract}
Streptococcus agalactiae (GBS) is a major source of human perinatal diseases and bovine mastitis. Erythromycin (Ery) and tetracycline (Tet) are usually employed for preventing human and bovine infections although resistance to such agents has become common among GBS strains. Ery and Tet resistance genes are usually carried by conjugative transposons (CTns) belonging to the Tn916 family, but their presence and transferability among GBS strains have not been totally explored. Here we evaluated the presence of Tet resistance genes (tet $\mathrm{M}$ and tet $\mathrm{O}$ ) and CTns among Ery-resistant (Ery- $\mathrm{R}$ ) and Ery-susceptible (Ery-S) GBS strains isolated from human and bovine sources; and analyzed the ability for transferring resistance determinants between strains from both origins. Tet resistance and int-Tn genes were more common among Ery- $\mathrm{R}$ when compared to Ery-S isolates. Conjugative transfer of all resistance genes detected among the GBS strains included in this study (ermA, ermB, mef, tet $\mathrm{M}$ and tet $\mathrm{O}$ ), in frequencies between $1.10^{-7}$ and $9.10^{-7}$, was possible from bovine donor strains to human recipient strain, but not the other way around. This is, to our knowledge, the first report of in vitro conjugation of Ery and Tet resistance genes among GBS strains recovered from different hosts.
\end{abstract}

Key words: Streptococcus agalactiae (GBS), conjugative transposons, erythromycin resistance, tetracycline resistance.

\section{Introduction}

Streptococcus agalactiae (group B Streptococcus; GBS) emerged as a major source of perinatal diseases in the 60's (Eickhoff et al., 1964), after a long history of contributing mostly to mastitis in cows. In Brazil, GBS prevalence among herds has been reported to be around $60 \%$ (Duarte $e t$ al., 2004; Keefe, 2012). Bovine mastitis control is easily achieved using intramammary infusions containing high levels of one or more antibiotics, including mainly penicillins, cephalosporins, tetracyclines, aminoglycosides and macrolides (Keefe, 2012). On the other hand, rates of gastrointestinal and urogenital colonization among humans range between 10 and 30\% (Simões et al., 2007; Linhares et $a l ., 2011)$. Most of this number is constituted by pregnant women, and penicillin or macrolides are the recommended drugs for intrapartum chemoprophylaxis (CDC, 2010).

GBS remains susceptible to penicillin, with rare exceptions (Kimura et al., 2011). Resistance to erythromycin (Ery), however, has emerged in the USA and Europe, with rates between 20 and 50\% (Dipersio and Dipersio, 2006; Sadowy et al., 2010). In Brazil, Ery-resistant (Ery-R) GBS strains usually don't exceed $10 \%$ of prevalence (D'Oliveira et al., 2003; Duarte et al., 2005; Palmeiro et al., 2010; Corrêa et al., 2011). Tetracycline (Tet) resistance rates are known to be as high as $70-80 \%$ among strains from both human and bovine origins (D'Oliveira et al., 2003; Duarte et al., 2004, 2005; Dogan et al., 2005; Gao et al., 2012). Resistance to tetracycline in GBS is typically mediated by the tet $\mathrm{M}$ gene, while Ery resistance is usually due to the pres-

Send correspondence to T.C.A. Pinto. Instituto de Microbiologia Paulo de Góes, Centro de Ciências da Saúde, Bloco I. Av. Carlos Chagas Filho 373, Cidade Universitária, Ilha do Fundão, 21941-902 Rio de Janeiro, RJ, Brazil. E-mail: tati.micro@gmail.com. 
ence of the ermB gene (Poyart et al., 2003). These resistance genes are usually present in conjugative transposons (CTns), which can be horizontally transferred; most of them belong to the Tn916-Tn1545 family (Roberts and Mullany, 2011).

Recently, we reported a considerably higher Ery resistance level among bovine GBS strains (27.6\%) when compared to human isolates $(4.0 \% ; \mathrm{p}=0.0277)$ in Brazil (Pinto et al., 2013). Moreover, in the same study, around $90 \%$ of both human and bovine isolates were Tet-resistant (Tet-R). The presence and transferability of CTns among GBS isolates, however, have not been totally explored. Therefore, in this study, we evaluated the presence of Tet resistance genes and CTns among Ery-R and Ery-S GBS strains isolated from human and bovine sources, and analyzed the ability for transferring erythromycin and tetracycline resistance determinants between strains from different origins.

\section{Materials and Methods}

\section{Bacterial strains}

Eighty-nine GBS strains were selected according to their susceptibility profile, among a collection previously evaluated by our group (Pinto et al., 2013), and clustered into three main groups as follows:

The first group comprised twenty-three Ery-R GBS strains, including fifteen of human and eight of bovine origin, which were also Tet-R and represented different Ery resistance genotypes. The second group included 23 erythromycin-susceptible (Ery-S)/Tet-R GBS strains, comprising twelve of human and eleven of bovine origin. In the third group, 43 Ery-S and Tet-susceptible (Tet-S) GBS strains were included.

\section{Detection of tetracycline resistance genes and int-Tn gene}

The presence of tet $\mathrm{M}$ and tet $\mathrm{O}$ genes was evaluated by PCR as previously described (Trzcinski et al., 2000). Likewise, the presence of the gene coding for the integrase of the Tn916-Tn1545 family of CTns was evaluated by PCR as recommended elsewhere (Poyart et al., 2003). DNA extraction was performed according to Sambrook et al. (1989).

\section{Statistical analysis}

The Student's $t$ test was employed and differences were considered statistically significant when $\mathrm{p}<0.05$.

\section{Filter mating experiments}

Seven Ery-R GBS strains were selected as donors according to their Ery resistance profile, while two Ery-S strains were selected as the recipients. Donors were susceptible to chloramphenicol while recipients were resistant to this drug. Their characteristics are illustrated in Table 1. Minimal inhibitory concentrations (MIC) of erythromycin, tetracycline and chloramphenicol (Sigma-Aldrich, St. Louis, MO, USA) were determined by the broth dilution method (CLSI, 2011) for the nine GBS strains.

Filter mating experiments were done using previous recommendations (Horaud et al., 1996), with the following modifications: strains were grown in Todd-Hewitt broth (THB; BD Difco, BD Diagnostics, Franklin Lakes, NJ, USA), and the initial inoculum was adjusted to $\mathrm{OD}_{540}$ of 0.4. Chloramphenicol, erythromycin and tetracycline were used as the selective drugs for transconjugants, with concentrations varying according to the MIC levels of each strain.

Frequency of conjugation was expressed as the number of transconjugants per colony forming unit (CFU) of re-

Table 1 - Characteristics of the nine Streptococcus agalactiae strains included in the filter mating conjugation experiments performed in this study.

\begin{tabular}{|c|c|c|c|c|c|c|}
\hline Strain & Clinical origin & Erythromycin genotype & Tetracycline genotype & int $-\mathrm{Tn}$ & Frequency $^{\mathrm{a}}$ & Added to the medium $^{\mathrm{b}}$ \\
\hline \multicolumn{7}{|c|}{ Donor strains } \\
\hline 87169 & Bovine & erm $\mathrm{A} / m e f$ & None & + & $1.10^{-7}$ & None \\
\hline 90003 & Human & mef & tet $\mathrm{M}$ & + & $9.10^{-7}$ & Erythromycin \\
\hline 96008 & Human & erm $\mathrm{B}$ & tet $\mathrm{O}$ & + & $9.10^{-7}$ & Tetracycline \\
\hline 96009 & Human & erm $\mathrm{B}$ & tet $\mathrm{O}$ & - & ND & NA \\
\hline 02031 & Human & erm $\mathrm{A}$ & tet $\mathrm{O}$ & - & ND & NA \\
\hline 06003 & Bovine & erm $\mathrm{B} / m e f$ & tet $\mathrm{M} /$ tet $\mathrm{O}$ & - & ND & NA \\
\hline 06005 & Bovine & erm $\mathrm{B} / \mathrm{mef}$ & tet $\mathrm{M} /$ tet $\mathrm{O}$ & + & $1.10^{-7}$ & Erythromycin/ tetracycline \\
\hline \multicolumn{7}{|c|}{ Recipient strains } \\
\hline 88596 & Human & None & None & - & NA & NA \\
\hline B66 & Bovine & None & None & - & NA & NA \\
\hline
\end{tabular}

${ }^{\mathrm{a}}$ Frequency of conjugation expressed as the number of transconjugants per cfu of recipient; ND, not determined since transconjugants were not detected; NA, not applicable.

${ }^{\mathrm{b}}$ Antimicrobials added to the conjugation medium in some replicas: erythromycin at $0.5 \mu \mathrm{g} / \mathrm{mL}$ and tetracycline at $4 \mu \mathrm{g} / \mathrm{mL}$; NA, not applicable. 
cipient. Donor and recipient control plates were included to discard the possibility of spontaneous mutation, and all the experiments were done in duplicates, in three independent assays. DNase (1 g/L) (Sigma-Aldrich) was added to the conjugation medium to exclude the possibility of transformation. Moreover, subinhibitory concentrations of erythromycin $(0.5 \mu \mathrm{g} / \mathrm{mL})$ and tetracycline $(4 \mu \mathrm{g} / \mathrm{mL})$ were also added in some replicas to verify their influence on conjugation frequency.

The transconjugants were isolated, identified as GBS using a Streptococcal Grouping Kit (Oxoid, Basingstoke, Hampshire, UK), and characterized regarding antimicrobial susceptibility profile (disk-diffusion and MIC), presence of resistance genes and of int-Tn gene, as described above.

\section{Results \\ Distribution of tet and int-Tn genes among Ery- $\mathrm{R}$ GBS strains}

The tet $\mathrm{M}$ gene was detected in fourteen of the twenty-three Ery-R strains $(60.9 \%)$, while tet $\mathrm{O}$ was found in seventeen $(73.9 \%)$. Ten strains harbored both genes simultaneously, and two had none of the genes. Combining Ery and Tet determinants, the most common genotype among Ery-R GBS strains was ermB/mefltet $\mathrm{M} /$ tetO.

A total of $87.0 \%(20 / 23)$ of the Ery-R GBS strains had the int-Tn gene, including thirteen from human origin and seven from bovine origin. Only two int-Tn-positive strains had no tet genes, and only one strain harboring a tet gene (tetO) did not present int-Tn.

\section{Distribution of tet and int-Tn genes among Ery-S/Tet-R GBS strains}

Among the twenty-three Ery-S/Tet-R GBS strains, tet $\mathrm{M}$ was detected in seven isolates $(30.4 \%)$, while tet $\mathrm{O}$ was observed in ten (43.5\%). Five strains had both genes, and eleven did not present any of them. A total of $65.2 \%$ $(15 / 23)$ harbored the int-Tn gene, including five from human origin and ten from bovine origin. Four int-Tn-positive strains had no tet genes, and only one tetO-positive strain did not present int-Tn.

\section{Distribution of tet and int-Tn genes among Ery-S/Tet-S GBS strains}

Among the forty-three Tet-S GBS strains, forty-two did not amplify any of the tet genes tested. One single Tet-S strain, isolated from human oropharynx and belonging to serotype Ia, had the tet $\mathrm{M}$ gene. A total of $11.6 \%$ (5/43) harbored the int-Tn gene, comprising three of human origin (tet $\mathrm{M}$-positive isolate included) and two of bovine origin.

\section{Conjugative transfer of resistance-associated genes}

Matings with the human GBS isolate as the recipient were successful when using four of the seven selected do- nors, in frequencies between $1.10^{-7}$ and $9.10^{-7}$ (Table 1). Addition of subinhibitory concentrations of erythromycin and/or tetracycline to the conjugation medium was a crucial factor for three of them. No transconjugants were observed when the bovine GBS isolate was used as the recipient strain.

All the resistance determinants observed among the selected GBS strains (erm $\mathrm{A}, \operatorname{erm} \mathrm{B}$, mef, tet $\mathrm{M}$ and tet $\mathrm{O}$ ) could be transferred in vitro, always in combination with int-Tn gene (Table 1). The three donor strains that did not generate transconjugants lacked the int-Tn gene.

\section{Discussion}

Contrasting with data from the literature (Poyart et al., 2003; Dipersio and Dipersio, 2006; Cochetti et al., 2007), tetO gene was the prevalent Tet determinant among both human and bovine GBS strains in this study. While only one Ery-R strain did not amplify any of the tet genes tested, 11 Ery-S did not present any tet gene. This statistically significant difference $(\mathrm{p}=0.0282)$ suggests a linkage between tet genes and erythromycin-resistance determinants among our strains.

There are multiple descriptions of association between tet $\mathrm{M}$ and erm $\mathrm{B}$ genes on the same mobile genetic element in Streptococcus pyogenes and Streptococcus pneumoniae (Varaldo et al., 2009). Such association, however, has been rarely evaluated in S. agalactiae (Varaldo et al., 2009; Haenni et al., 2010), and might be underestimated.

The int-Tn gene was detected in $11.6 \%$ of the Ery$\mathrm{S} /$ Tet-S GBS strains, in $65.2 \%$ of the Ery-S/Tet-R strains, and in $87.0 \%$ of the Ery-R/Tet-R isolates, suggesting an association between resistance determinants and CTns $(\mathrm{p}=0.0334)$.

Only one strain showing phenotypic susceptibility to Tet harbored the tet $\mathrm{M}$ gene, in combination with the int-Tn gene. This strain presented an inhibition zone indicative of Tet susceptibility in the disk-diffusion test, which was confirmed by MIC levels $(2 \mu \mathrm{g} / \mathrm{mL})$. Although reported for other streptococcal species, such as $S$. pneumoniae (Cochetti et al., 2007) and S. pyogenes (Brenciani et al., 2007), and for some bovine GBS isolates (Gao et al., 2012), the reasons behind the lack of expression of such resistance gene still have to be evaluated. Possible explanations include distant, weak or absent promoter, or presence of mutations (Gao et al., 2012). However, although in a silent form, they can still be carried by Tn916-related genetic elements (Cochetti et al., 2007).

Although tet $\mathrm{M}$ is the typical Tet resistance determinant shared among the members of Tn916-Tn1545 family, mobile elements carrying other less common tetracycline resistance genes, such as tetO (Varaldo et al., 2009; Brenciani et al., 2010) and tetS (Haenni et al., 2010), have been reported. Likewise, a variety of Ery resistance genes, such 
as mef $\mathrm{A}$ and erm $\mathrm{A}$, besides the most commonly found erm $\mathrm{B}$, have also been associated with tet genes and CTns, mainly in S. pyogenes isolates (Brenciani et al., 2007; Varaldo et al., 2009). Indeed, all the five resistanceassociated genes detected among the GBS strains included in this study (erm $\mathrm{A}, e r m \mathrm{~B}$, mef, tet $\mathrm{M}$ and tet $\mathrm{O}$ ) could be transferred in vitro, in different combinations. Moreover, no transconjugants were observed when using donor strains presenting identical genotypes but lacking the int-Tn gene (Table 1), suggesting the association of lateral dissemination of resistance genes with CTns.

In this study, conjugation was evident from bovine donor strains to human recipient strain, but not from human donor strains to bovine recipient strain. Additional experiments are required to check whether this limitation was strain-specific, since only one bovine strain was tested as the recipient, or if it is universally observed for bovine isolates. Despite this fact, the higher resistance levels observed among bovine isolates and their probable transmission to humans uncover possibilities of a bovine origin for erythromycin and tetracycline resistance among human GBS isolates.

Conjugation frequencies ranged between $1.10^{-7}$ and $9.10^{-7}$, which are similar to indexes observed by other authors for other streptococcal species (Giovanetti et al., 2002; Martel et al., 2005), but represent numbers 2 to 90 times higher than those previously observed for bovine GBS isolates (Haenni et al., 2010).

The addition of Ery and/or Tet in the conjugation medium was a decisive step for three of the four successful conjugation experiments, as it was previously suggested (Bahl et al., 2004), indicating the important role of selective pressure in the dissemination of resistance determinants. In the veterinary field, this selective pressure is represented by the intramammary infusions, which are slowly released for therapeutic purposes. As consequences, active levels of antimicrobials are maintained for an extended period of time and drug residues can be found in the milk of treated cows (Keefe, 2012).

Genomic studies have demonstrated the presence of CTns and the importance of horizontal gene transfer to the evolutionary process of GBS (Brochet et al., 2008). These elements usually carry resistance determinants and their dissemination is probably also driven by the abusive usage of antimicrobials. High Tet resistance rates currently observed among GBS isolates, and possibly driven by mobile genetic elements such as those from the Tn916 family, indicate the danger of a similar scenario for macrolides in the future. Although some CTns carrying Ery and Tet resistance determinants had been described among GBS strains (Marimón et al., 2005; Achard and Leclercq, 2007), the transferability of such elements between human and bovine isolates had never been demonstrated. Therefore, this is, to our knowledge, the first report of in vitro conjugation of Ery and Tet resistance genes, in combination with int-Tn gene, among GBS strains recovered from different hosts.

\section{Acknowledgments}

This work was supported by CNPq, FAPERJ, CAPES, PRONEX, The Thrasher Research Fund.

\section{References}

Achard A, Leclercq R (2007) Characterization of a small mobilizable transposon, MTnSag1, in Streptococcus agalactiae. J Bacteriol 189:4328-4331.

Bahl MI, Sorensen SJ, Hansen LH, Licht TR (2004) Effect of tetracycline on transfer and establishment of the tetracycline-inducible conjugative transposon Tn916 in the guts of gnotobiotic rats. Appl Environ Microbiol 70:758-764.

Brenciani A, Bacciaglia A, Vecchi M, Vitali LA, Varaldo PE, Giovanetti E (2007) Genetic elements carrying ermB in Streptococcus pyogenes and association with tet $\mathrm{M}$ tetracycline resistance gene. Antimicrob Agents Chemother 51:1209-1216.

Brenciani A, Bacciaglia A, Vignaroli C, Pugnaloni A, Varaldo PE, Giovanetti E (2010) m46.1, the main Streptococcus pyogenes element carrying $\operatorname{mef}(\mathrm{A})$ and tet(O) genes. Antimicrob Agents Chemother 54:221-229.

Brochet M, Couve E, Glaser P, Guedon G, Payot S (2008) Integrative conjugative elements and related elements are major contributors to the genome diversity of Streptococcus agalactiae. J Bacteriol 190:6913-6917.

Centers for Disease Control and Prevention (CDC) (2010) Prevention of Perinatal Group B Streptococcal Disease - Revised Guidelines from CDC, 2010. MMWR Recomm Rep 59 (No. RR-10):1-32.

Clinical and Laboratory Standards Institute (CLSI) (2011) Performance standards for antimicrobial susceptibility testing: twentieth-one informational supplement. M100-S21.

Cochetti I, Tili E, Vecchi M, Manzin A, Mingoia M, Varaldo PE, Montanari MP (2007) New Tn916-related elements causing ermB-mediated eryhtromycin resistance in tetracycline susceptible pneumococci. J Antimicrob Chemother 60:127-131.

Corrêa AB, Silva LG, Pinto TCA, Oliveira IC, Fernandes FG, Costa NS, Mattos MC, Fracalanzza SE, Benchetrit LC (2011) The genetic diversity and phenotypic characterisation of Streptococcus agalactiae isolates from Rio de Janeiro, Brazil. Mem Inst Oswaldo Cruz 106:1002-1006.

D'Oliveira REC, Barros RR, Mendonça CRV, Teixeira LM, Castro ACD (2003) Susceptibility to antimicrobials and mechanisms of erythromycin resistance in clinical isolates of Streptococcus agalactiae from Rio de Janeiro, Brazil. J Med Microbiol 52:1029-1030.

Dipersio LP, Dipersio JR (2006) High rates of erythromycin and clindamycin resistance among OBGYN isolates of group B Streptococcus. Diagn Microbiol Infect Dis 54:79-82.

Dogan B, Schukken YH, Santisteban C, Boor KJ (2005) Distribution of serotypes and antimicrobial resistance genes among Streptococcus agalactiae isolates from bovine and human hosts. J Clin Microbiol 43:5899-5906.

Duarte RS, Miranda OP, Bellei BC, Brito MAVP, Teixeira LM (2004) Phenotypic and molecular characteristics of Streptococcus agalactiae isolates recovered from milk of dairy cows in Brazil. J Clin Microbiol 42:4214-4222.

Duarte RS, Bellei BC, Miranda OP, Brito MAVP, Teixeira LM (2005) Distribution of antimicrobial resistance and viru- 
lence-related genes among Brazilian group B streptococci recovered from bovine and human sources. Antimicrob Agents Chemother 49:97-103.

Eickhoff TC, Klein JO, Daly AK, Ingall D, Finland M (1964) Neonatal sepsis and other infections due to group B betahemolytic streptococci. N Engl J Med 271:1221-1228.

Gao J, Yu FQ, Luo LP, He JZ, Hou RG, Zhang HQ, Li SM, Su JL, Han B (2012) Antibiotic resistance of Streptococcus agalactiae from cows with mastitis. Vet J 194:423-424.

Giovanetti E, Magi G, Brenciani A, Spinaci C, Lupidi R, Facinelli $\mathrm{B}$, Varaldo PE (2002) Conjugative transfer of the ermA gene from eryhtromycin-resistant Streptococcus pyogenes to macrolide-susceptible $S$. pyogenes, Enterococcus faecalis and Listeria innocua. J Antimicrob Chemother 50:249-252.

Haenni M, Saras E, Bertin S, Leblond P, Madec JY, Payot S (2010) Diversity and mobility of integrative and conjugative elements in bovine isolates of Streptococcus agalactiae, $S$. dysgalactiae subsp. dysgalactiae, and S. uberis. Appl Environ Microbiol 76:7957-7965.

Horaud T, Cespedes G, Trieu-Cuot P (1996) Chromosomal gentamicin resistance transposon Tn3706 in Streptococcus agalactiae B128. Antimicrob Agents Chemother 40:10851090.

Keefe G (2012) Update on control of Staphylococcus aureus and Streptococcus agalactiae for management of mastitis. Vet Clin Food Anim 28:203-216.

Kimura K, Nagano N, Nagano Y, Wachino J, Suzuki S, Shibayama K, Arakawa Y (2011) Predominance of sequence type 1 group with serotype VI among group B streptococci with reduced penicillin susceptibility identified in Japan. J Antimicrob Chemother 66:2460-2464.

Linhares JJ, Cavalcante Neto PG, Vasconcelos JL, Saraiva TdeV, Ribeiro AM, Siqueira TM, Rocha FR (2011) Prevalência de colonização por Streptococcus agalactiae em gestantes atendidas em maternidade do Ceará, no Brasil, correlacionando com os resultados perinatais. Rev Bras Ginecol Obstet 33:395-400.

Marimón JM, Valiente A, Ercibengoa M, García-Arenzanaj M, Perez-Trallero E (2005) Erythromycin resistance and genetic elements carrying macrolide efflux genes in Streptococcus agalactiae. Antimicrob Agents Chemother 49:5069-5074.
Martel A, Decostere A, Leener ED, Marien M, Graef ED, Heyndrickx M, Goossens H, Lammens C, Devriese LA, Haesebrouck F (2005) Comparison and transferability of the erm $\mathrm{B}$ genes between human and farm animal streptococci. Microb Drug Resist 11:295-302.

Palmeiro JK, Dalla-Costa LM, Fracalanzza SE, Botelho AC, da Silva Nogueira K, Scheffer MC, de Almeida Torres RS, de Carvalho NS, Cogo LL, Madeira HM (2010) Phenotypic and genotypic characterization of group B streptococcal isolates in southern Brazil. J Clin Microbiol 48:4397-4403.

Pinto TCA, Costa NS, Souza ARV, da Silva LG, Corrêa ABA, Fernandes FG, Oliveira ICM, de Mattos MC, Rosado AS, Benchetrit LC (2013) Distribution of serotypes and evaluation of antimicrobial susceptibility among human and bovine Streptococcus agalactiae strains isolated in Brazil between 1980 and 2006. Braz J Infect Dis 17:131-136.

Poyart C, Jardy L, Quesne G, Berche P, Trieu-Cuot P (2003)Genetic basis of antibiotic resistance in Streptococcus agalactiae strains isolated in a French hospital. Antimicrob Agents Chemother 47:794-797.

Roberts AP, Mullany P (2011) Tn916-like genetic elements: a diverse group of modular mobile elements conferring antibiotic resistance. FEMS Microbiol Rev 35:856-871.

Sadowy E, Matynia B, Hryniewicz W (2010) Population structure, virulence factors and resistance determinants of invasive, non-invasive and colonizing Streptococcus agalactiae in Poland. J Antimicrob Chemother 6:1907-1914.

Sambrook J, Fritsch EF, Maniatis T (1989) Molecular cloning: a laboratory manual. Cold Spring Harbor Laboratory Press, New York, NY.

Simões JA, Alves VMN, Fracalanzza SEL, Camargo RPS, Mathias L, Milanez HMBP, Brolazo EM (2007) Phenotypical characteristics of group B Streptococcus in parturients. Braz J Infect Dis 11:261-266.

Trzcinski K, Cooper BS, Hryniewicz W, Dowson CG (2000) Expression of resistance to tetracyclines in strains of methicillin-resistant Staphylococcus aureus. J Antimicrob Chemother 45:2778-2781.

Varaldo PE, Montanari MP, Giovanetti E (2009) Genetic elements responsible for erythromycin resistance in streptococci. Antimicrob Agents Chemother 53:343-353.

All the content of the journal, except where otherwise noted, is licensed under a Creative Commons License CC BY-NC. 